\title{
Estrogen Replacement Therapy
}

National Cancer Institute

\section{Source}

National Cancer Institute. Estrogen Replacement Therapy. NCI Thesaurus. Code C15231.

The administration of estrogen, especially in postmenopausal women, to relieve menopausal symptoms and to protect against osteoporosis and heart disease. (Bartleby.com) 